\title{
Atrial rhythm influences catheter tissue contact during radiofrequency catheter ablation of atrial fibrillation: comparison of contact force between sinus rhythm and atrial fibrillation
}

\author{
Hisao Matsuda ${ }^{1}$ Abdul Shokor Parwani ${ }^{1} \cdot$ Philipp Attanasio $^{1} \cdot$ Martin Huemer $^{1}$ • \\ Alexander Wutzler ${ }^{1} \cdot$ Florian Blaschke $^{1} \cdot$ Wilhelm Haverkamp $^{1} \cdot$ Leif-Hendrik Boldt $^{1}$
}

Received: 23 February 2015 / Accepted: 16 October 2015 / Published online: 26 October 2015

(c) The Author(s) 2015. This article is published with open access at Springerlink.com

\begin{abstract}
Catheter tissue contact force (CF) is an important factor for durable lesion formation during radiofrequency catheter ablation (RFCA) of atrial fibrillation (AF). Since $\mathrm{CF}$ varies in the beating heart, atrial rhythm during RFCA may influence CF. A high-density map and RFCA points were obtained in 25 patients undergoing RFCA of AF using a CF-sensing catheter (Tacticath, St. Jude Medical). The operators were blinded to the CF information. Contact type was classified into three categories: constant, variable, and intermittent contact. Average CF and contact type were analyzed according to atrial rhythm (SR vs. AF) and anatomical location. A total of 1364 points (891 points during SR and 473 points during AF) were analyzed. Average CFs showed no significant difference between SR $(17.2 \pm 11.3 \mathrm{~g})$ and $\mathrm{AF}(17.2 \pm 13.3 \mathrm{~g} ; p=0.99)$. The distribution of points with an average $\mathrm{CF}$ of $\geq 20$ and $<10 \mathrm{~g}$ also showed no significant difference. However, the distribution of excessive $\mathrm{CF}$ ( $\mathrm{CF} \geq 40 \mathrm{~g}$ ) was significantly higher during $\mathrm{AF}(7.4 \%)$ in comparison with $\mathrm{SR}(4.2 \%$; $p<0.05$ ). At the anterior area of the right inferior pulmonary vein (RIPV), the average CF during AF was significantly higher than during SR $(p<0.05)$. Constant contact was significantly higher during AF (32.2\%) when compared to SR $(9.9 \% ; p<0.01)$. Although the average CF was not different between atrial rhythms, constant contact was more often achievable during AF than it was during SR. However, excessive CF also seems to occur more frequently during AF especially at the anterior part of RIPV.
\end{abstract}

Hisao Matsuda

h.matsuda@marianna-u.ac.jp;

hisao.matsuda@marianna-u.ac.jp

1 Cardiology, Campus Virchow Klinikum, CharitéUniversitätsmedizin Berlin, Augustenburger Platz 1, 13353 Berlin, Germany
Keywords Atrial fibrillation - Catheter ablation · Contact force $\cdot$ Pulmonary vein isolation $\cdot$ Sinus rhythm

\section{Introduction}

Radiofrequency catheter ablation (RFCA) is an accepted treatment option for symptomatic and drug resistance atrial fibrillation (AF) [1]. The most commonly used ablation strategy is circumferential pulmonary vein isolation (PVI) around the ipsilateral pulmonary vein ostia using irrigated RF current.

Besides power and duration of RF delivery, catheter tissue contact has been shown to be an important factor for lesion size, transmurality and durable lesion formation during RFCA of AF [2]. Insufficient tissue contact may result in incomplete or transient lesion formation, while excessive contact increases the risk of major complications. A novel technology was developed that integrates a contact force (CF) sensor at the tip of an open-irrigated RF catheter [2], which allows continuous real-time and direct measurement of the CF between catheter tip and target tissue.

Some clinical trials $[3,4]$ showed that CF correlates with clinical outcome in patients with AF undergoing RFCA for AF using CF-sensing catheters. During PVI, an average CF of $\geq 20 \mathrm{~g}$ is an optimal target to avoid insufficient lesion formation, while an average $\mathrm{CF}$ of $<10 \mathrm{~g}$ is correlated with a recurrence of AF [3-5]. However, achievement of good tissue contact is difficult in some cases even despite knowledge of CF. Influences of the anatomical situation $[3,4$, 6] upon $\mathrm{CF}$ were recently reported. Respiratory condition has also been shown to be a factor influencing CF [7] and may cause left atrial remodeling [8]. Since CF varies in the beating heart, atrial rhythm during the procedure may also influence tissue contact. To our knowledge, a direct 
comparison of $\mathrm{CF}$ according to atrial rhythm during $\mathrm{RF}$ for $\mathrm{AF}$ using CF-sensing catheters has not yet been published. Therefore, the influence of atrial rhythm upon CF is still quite unclear. The objective of this study was to evaluate the influence of atrial rhythm during ablation upon CF.

\section{Methods}

\section{Study population}

Twenty-five patients with symptomatic, drug-resistant $\mathrm{AF}$ who underwent catheter ablation for $\mathrm{AF}$ at our center between October 2013 and August 2014 were prospectively enrolled in this study. Written informed consent was obtained from all patients. This study was approved by the Charité Institutional Ethics Committee (EA1/278/14).

\section{Pulmonary vein isolation and $\mathrm{CF}$ measurement}

Before procedure, any patient with a left atrium (LA) or left atrial appendage thrombus was excluded using transesophageal echocardiography. The procedure was performed with deep sedation using midazolam and continuous infusion of propofol.

Esophageal temperature was monitored during the whole procedure using a SensiTherm temperature probe (St. Jude Medical). A 6-F decapolar catheter was positioned in the coronary sinus through the left femoral vein. Through the right femoral vein, a steerable 8.5-F long sheath (Agilis, St. Jude Medical) and a non-steerable 8.5-F long sheath (SL0, St. Jude Medical) were introduced into the LA using single transseptal puncture guided by fluoroscopy and pressure monitoring at the needle tip. In one case, transesophageal echocardiography was also used as guidance for the transseptal puncture because of a prior surgical patch closure operation of an atrial septal defect. After transseptal puncture, the CF sensing ablation catheter (TactiCath, St. Jude Medical) was positioned in the left ventricle through the Agilis sheath, and LA angiography was performed during left ventricular high rate pacing (200 beats $/ \mathrm{min}$ ).

LA geometry was acquired using a spiral mapping catheter (IBI Inquiry Optima, St. Jude Medical) in combination with the 3D mapping system (EnSite Navix Velocity, St. Jude Medical). Directly after transseptal puncture, heparin was administered intravenously at a dose of $100 \mathrm{U} / \mathrm{kg}$ body weight. Thereafter, activated clotting time (ACT) was checked every $30 \mathrm{~min}$ and more heparin was administered when necessary to maintain an ACT of $>300 \mathrm{~s}$.

An open-irrigated RF catheter with a CF sensor (Tacticath, St. Jude Medical) was used in all cases. The CF sensing catheter is a steerable 7-F, 3.5-mm tip open irrigated ablation catheter which allows continuous real-time and direct measurement of the $\mathrm{CF}$ between the tissue and the catheter-tip [9]. The CF sensor is a triaxial force sensor located between the second and third electrode and has a resolution and sensitivity of $1 \mathrm{~g}$ in a bench test [2]. The real-time $\mathrm{CF}$ is measured every $50 \mathrm{~ms}$ and displayed continuously as the number of grams. The live CF information was not available for operators during the procedure.

For $\mathrm{CF}$ analysis, each pulmonary vein was divided into four quadrants: anterior-superior, anterior-inferior, posterior-superior, and posterior-inferior. At each quadrant, at least two points were achieved for CF mapping. When the patients were in $\mathrm{AF}$ at the beginning of the procedure, $\mathrm{CF}$ mapping was first performed during AF before RFCA. Therefore, the CF sensing catheter was positioned at the designated circumferential lesion line and kept stable without energy delivery. CF parameters were recorded at these points and tagged in the 3D geometry for later reference. After CF mapping during AF, external cardioversion was performed to restore sinus rhythm (SR). RFCA was applied during SR in those patients in which SR could be restored and $\mathrm{CF}$ information was recorded during $\mathrm{RF}$ ablation at the same points previously analyzed during AF. To ensure comparable conditions, each RF pulse was delivered without dragging manoeuver but with a "point by point" technique.

When the patients were in SR at the beginning of the procedure, $\mathrm{CF}$ data were recorded during $\mathrm{SR}$ and $\mathrm{AF}$ was induced thereafter. Ablation was then performed during $\mathrm{AF}$ at the same points previously tagged in the 3-D geometry.

In those patients who could not be cardioverted or in whom AF induction failed, CF information was only available for either SR or AF.

RF energy was delivered in a power-control mode and was limited to $35 \mathrm{~W}$ and $60 \mathrm{~s}$ for all locations in the LA. When esophageal temperature increased to more than $39^{\circ} \mathrm{C}$, energy delivery was stopped immediately and lower RF energy in the range of 20-25 W was applied.

Isolation of each PV was confirmed by entrance block using the spiral mapping catheter. When PVI was not achieved with circumferential ablation, earliest PV potentials were targeted sequentially until complete isolation was achieved.

When atrial tachycardia remained after the completion of PVI, roof line ablation or mitral isthmus ablation was added to PVI, depending on the mechanism of atrial tachycardia.

\section{Evaluation of CF parameter}

At each mapping or ablation point, 3D anatomical location was recorded. Average CF and the type of tissue contact was evaluated at each point.

According to the average $\mathrm{CF}$, each point was categorized as "low contact" (average CF $<10 \mathrm{~g}$ ), "sufficient contact" 


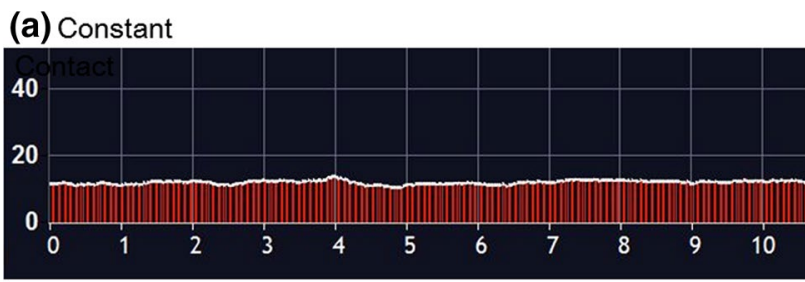

(b) Variable

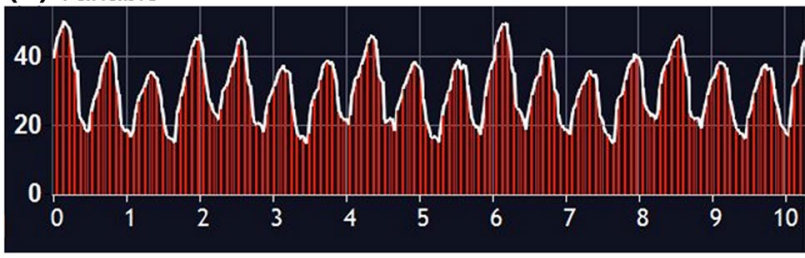

(c) Intermittent

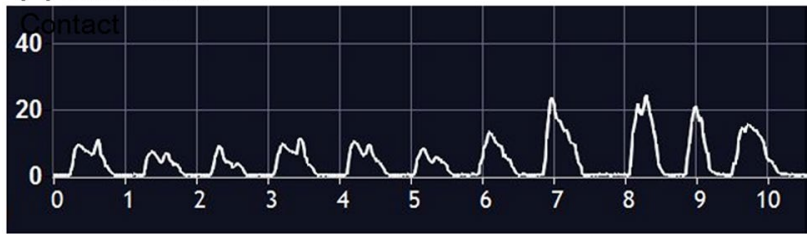

Fig. 1 Definition of contact type. a Constant contact indicating that the difference of minimal $\mathrm{CF}$ and maximal $\mathrm{CF}$ was within $10 \mathrm{~g}$. b Variable contact indicating that the difference of minimum $\mathrm{CF}$ and maximum $\mathrm{CF}$ was more than $10 \mathrm{~g}$. c Intermittent contact indicating that the contact type with a nadir of $0 \mathrm{~g} \mathrm{CF}$ (loss of contact) is at least $50 \mathrm{~ms}$, regardless of CF difference between minimum and maximum $\mathrm{CF}$

(average $\mathrm{CF} \geq 20 \mathrm{~g}$ ), and "excessive contact" (average $\mathrm{CF} \geq 40 \mathrm{~g})$.

The type of tissue contact was categorized into three groups (Fig. 1) and was defined as follows:

1. Constant contact: the difference of minimal $\mathrm{CF}$ and maximal $\mathrm{CF}$ was within $10 \mathrm{~g}$.

2. Variable contact: the difference of minimal $\mathrm{CF}$ and maximal $\mathrm{CF}$ was more than $10 \mathrm{~g}$.

3. Intermittent contact: regardless of $\mathrm{CF}$ difference during mapping or ablation, but with a nadir of $0 \mathrm{~g} \mathrm{CF}$ (loss of contact) of at least $50 \mathrm{~ms}$.

Average CF and type of contact were analyzed according to atrial rhythms (SR vs. AF).

\section{Statistical analysis}

All continuous variables were expressed as mean \pm standard deviation. A Student $t$ test and a Chi square test were used for statistical analysis. A two-tailed probability value of $p<0.05$ was considered to be statistically significant. All statistical analyses were performed using SPSS version 22 (SPSS Inc., Chicago, IL, USA).
Table 1 Clinical characteristics

\begin{tabular}{ll}
\hline Parameter & $N=25$ \\
\hline Age (years) & $63.6 \pm 7.4$ \\
Male patients & $14(56.0 \%)$ \\
BMI $\left(\mathrm{kg} / \mathrm{m}^{2}\right)$ & $27.6 \pm 6.6$ \\
Persistent AF & $10(40.0 \%)$ \\
Left atrial dimension $(\mathrm{mm})$ & $42.3 \pm 5.3$ \\
Ejection fraction $(\%)$ & $54.8 \pm 9.7$ \\
CHA2DS2-VASc score & $2.0 \pm 1.3$ \\
Hypertension & $18(72.0 \%)$ \\
Diabetes mellitus & $1(4.0 \%)$ \\
Vascular disease & $7(28.0 \%)$ \\
Total procedure time (min) & $142 \pm 26$ \\
Total RF time (min) & $30.2 \pm 8.0$ \\
\hline
\end{tabular}

Continuous variables are shown as mean $\pm \mathrm{SD}$

$B M I$ body mass index, $A F$ atrial fibrillation, $R F$ radiofrequency

\section{Results}

\section{Clinical characteristics}

A total of 1364 points (891 points during SR and 473 points during $\mathrm{AF}$ ) were acquired and analyzed in 25 patients (age $63.6 \pm 7.4$ years, $44 \%$ female). Patient characteristics are described in Table 1. CF data during SR could be recorded in 22 patients and during AF in 15 patients. All pulmonary veins were successfully isolated in all of the 25 patients. The numbers of data points in each patient according to atrial rhythms is depicted in Table 2 . The procedures were all performed by two experienced operators each who have gathered experience from more than 250 cases of PVI. Also, there was no difference of CF data between the operators.

\section{Average contact force during SR and AF}

The distribution of average CF showed a high variability in both atrial rhythms (1-90 g during SR, 0-68 g during AF). Peak distribution was $21.5 \%$ in the range of $5-10 \mathrm{~g}$ during SR and $17.5 \%$ in the range of 10-15 g during AF. The distribution of $\mathrm{CF}$ according to atrial rhythm is shown in Fig. 2. The average CF was $17.2 \pm 11.3 \mathrm{~g}$ during SR and $17.2 \pm 13.3 \mathrm{~g}$ during AF. There was no significant difference in a comparison of average CF between SR and AF $(p=0.99)$ (Fig. 3). In a sub-analysis, when we only analyzed those patients in which we could achieve the data points during both atrial rhythms, the average CF still showed no significant difference between atrial rhythms $(16.9 \pm 11.6 \mathrm{~g}$ during SR and $16.0 \pm 13.3 \mathrm{~g}$ during AF; $p=0.30)$. 
Table 2 The numbers of data points in each patient during SR and AF

\begin{tabular}{|c|c|c|c|}
\hline Case number & During SR & During AF & Total \\
\hline 1 & 51 & 0 & 51 \\
\hline 2 & 34 & 12 & 46 \\
\hline 3 & 36 & 6 & 42 \\
\hline 4 & 0 & 90 & 90 \\
\hline 5 & 50 & 0 & 50 \\
\hline 6 & 3 & 51 & 54 \\
\hline 7 & 43 & 28 & 71 \\
\hline 8 & 54 & 0 & 54 \\
\hline 9 & 67 & 0 & 67 \\
\hline 10 & 30 & 0 & 30 \\
\hline 11 & 54 & 22 & 76 \\
\hline 12 & 16 & 15 & 31 \\
\hline 13 & 40 & 0 & 40 \\
\hline 14 & 13 & 20 & 33 \\
\hline 15 & 44 & 0 & 44 \\
\hline 16 & 91 & 0 & 91 \\
\hline 17 & 0 & 46 & 46 \\
\hline 18 & 67 & 19 & 86 \\
\hline 19 & 48 & 37 & 85 \\
\hline 20 & 38 & 15 & 53 \\
\hline 21 & 4 & 55 & 59 \\
\hline 22 & 32 & 0 & 32 \\
\hline 23 & 38 & 0 & 38 \\
\hline 24 & 0 & 34 & 34 \\
\hline 25 & 38 & 23 & 61 \\
\hline Total $(N=25)$ & 891 & 473 & 1364 \\
\hline
\end{tabular}

$S R$ sinus rhythm, $A F$ atrial fibrillation

There was no difference observed in the ratio of low contact (29.3\% during SR vs. $32.8 \%$ during AF; $p=0.18$ ) or in the ratio of sufficient contact $(36.0 \%$ during SR and $34.2 \%$ during AF; $p=0.93$ ) (Fig. 4). In contrast to these results, the ratio of excessive $\mathrm{CF}$ was significantly higher during AF (7.4 \%) than it was during SR $(4.2 \% ; p<0.05)$ (Fig. 4).

\section{Contact type according to atrial rhythm}

The ratio of contact type during SR was $9.9 \%$ for constant contact, $78.4 \%$ for variable contact, and $11.8 \%$ for intermittent contact. During AF, the ratio of contact type was $33.1,43.6$, and $23.3 \%$, respectively. The percentage of points with constant contact was significantly higher during AF when compared with SR $(p<0.01)$ (Fig. 5). When we analyzed only those patients in whom we could achieve the data points during both atrial rhythms, the ratio of constant contact was significantly higher during AF $(29.0 \%)$ than during SR $(8.0 \% ; p<0.01)$.

When we analyzed only those points with optimal contact (excluding those points with low or excessively high contact), the percentage of points with constant contact was still significantly higher during AF (39.0\%) than it was during SR $(12.5 \% ; p<0.01)$ (Fig. 5).

\section{CF comparison between $S R$ and AF according to anatomical location}

Average CF was generally higher at the right pulmonary veins (RPV) than it was at the left pulmonary veins (LPV). Average CF at the RPV was significantly higher compared with the LPV during both atrial rhythms (during SR $18.2 \pm 11.7 \mathrm{~g}$ at the RPV vs. $16.4 \pm 10.4 \mathrm{~g}$ at the LPV; $p<0.05$, during AF $20.1 \pm 14.4 \mathrm{~g}$ at the RPV vs. $14.1 \pm 11.0 \mathrm{~g}$ at the LPV; $p<0.01)$. Lowest CF was observed at the LPV from anterior-inferior of LSPV $(13.3 \pm 8.8 \mathrm{~g})$ and down to anterior-inferior of LIPV $(12.0 \pm 9.4 \mathrm{~g})$. At this anatomical location (the LA ridge area), there was no significant difference of average CF between SR and AF (Fig. 6), but the proportion of constant contact was lower than in all other areas analyzed. The percentage of points with constant
Fig. 2 Contact force distribution according to atrial rhythm. Relative distribution of the average contact force. Distribution of contact force of 1364 points in 25 patients. $S R$ sinus rhythm, $A F$ atrial fibrillation

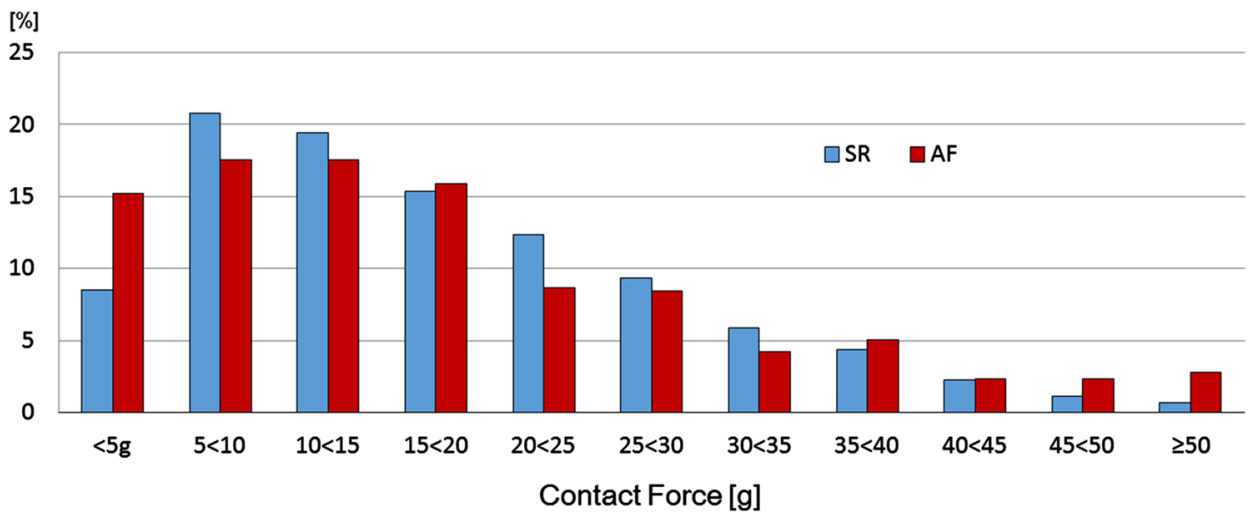




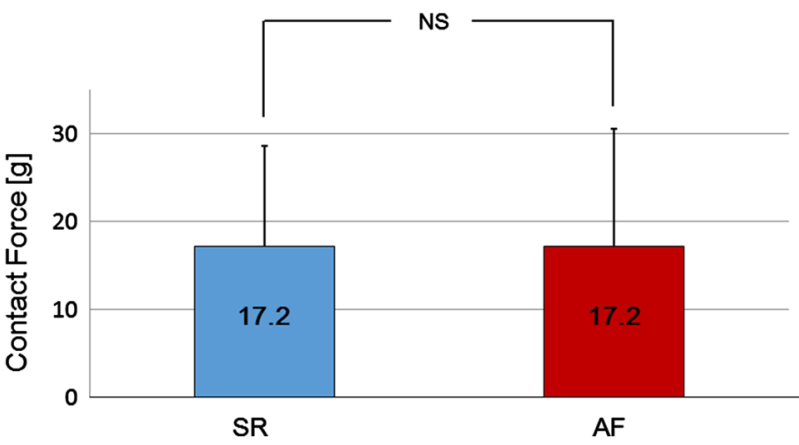

Fig. 3 Average contact force during sinus rhythm and atrial fibrillation. The average CF showed no significant difference between atrial rhythms ( $p=0.99)$. $S R$ sinus rhythm, $A F$ atrial fibrillation, $N S$ no significant difference contact in the LA ridge area was significantly higher during AF than it was during $\mathrm{SR}(p<0.01)$. The same holds true for the other anatomical locations mentioned here (Fig. 7).

At the anterior-inferior RIPV the highest average $\mathrm{CF}$ of all locations was achieved $(25.7 \pm 13.2 \mathrm{~g})$. Average CF during AF was significantly higher than SR at the anterior-superior $(18.1 \pm 11.7 \mathrm{~g}$ during $\mathrm{SR}$ vs $25.9 \pm 15.1 \mathrm{~g}$ during AF, $p<0.05)$ and anterior-inferior of RIPV $(23.4 \pm 11.5 \mathrm{~g}$ during SR vs $30.5 \pm 15.5 \mathrm{~g}$ during AF, $p<0.05)$. Except for the anterior part of the RIPV, there was no significant difference of average CF between $\mathrm{SR}$ and AF in relation to the anatomical location (Fig. 6). (a) low contact $(\mathrm{CF}<10 \mathrm{~g})$

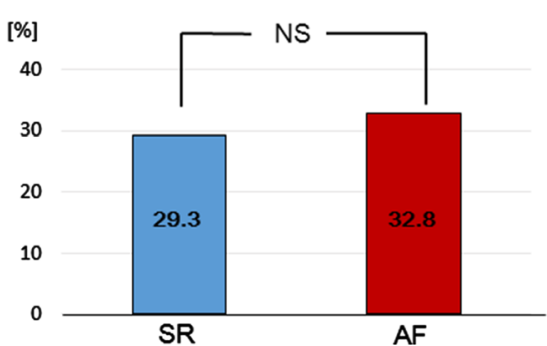

(b) sufficient contact $(C F \geq 20 \mathrm{~g})$

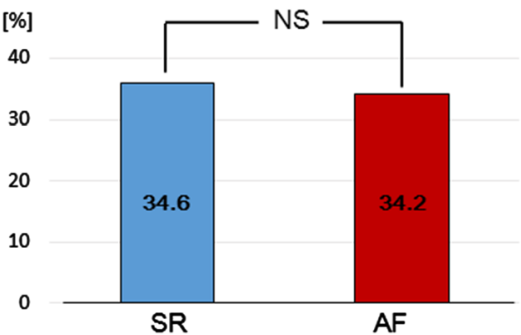

(c) excessive high contact $(\mathrm{CF} \geq 40 \mathrm{~g})$

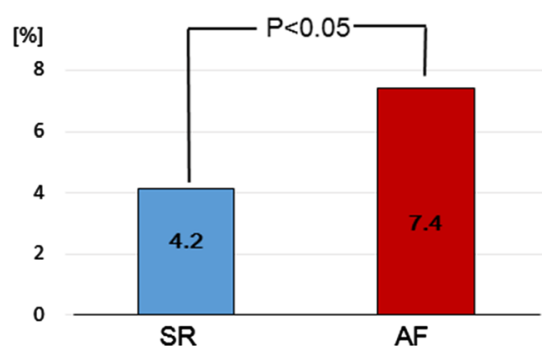

Fig. 4 Proportion of each contact force category during SR and AF. The ratio of a low contact and $\mathbf{b}$ sufficient contact showed no significant difference between SR and AF. In contrast to these results, the ratio of $\mathbf{c}$ excessive contact was significantly higher during $\mathrm{AF}$ than it was during SR. $S R$ sinus rhythm, $A F$ atrial fibrillation, $N S$ no significant difference (a)

constant contact

(b)

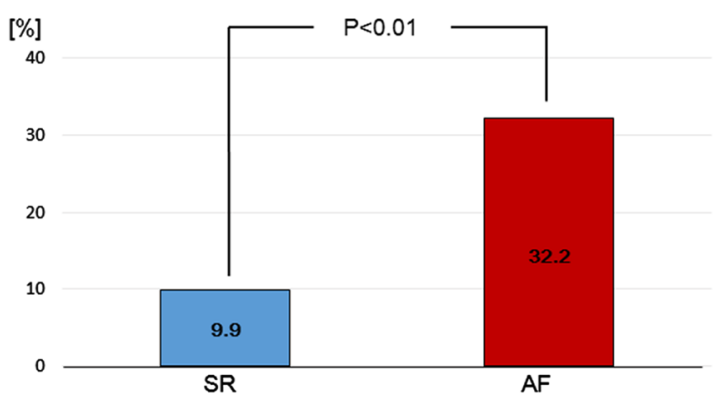

Fig. 5 Proportion of constant contact during SR and AF. a The constant contact was significantly more achievable during AF than during SR $(p<0.01)$. b When only analyzing those points with optimal contact (excluding those points with low or excessively high contact, b)

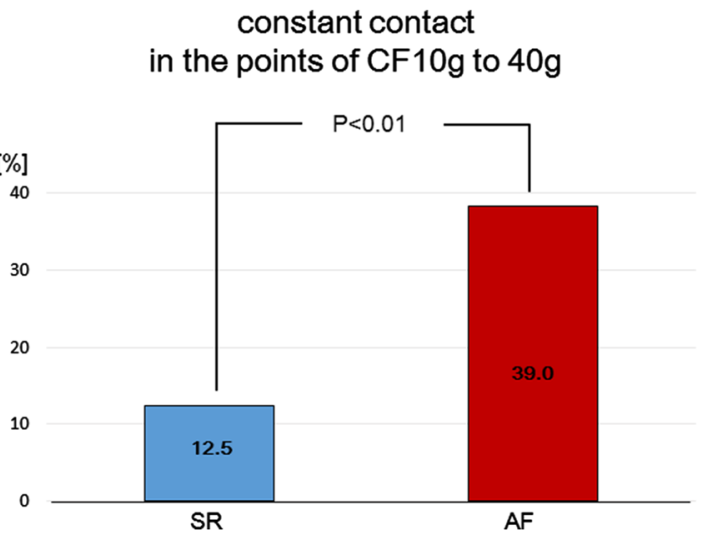

i.e. $\mathrm{CF}$ between 10 and $40 \mathrm{~g}$ ) the percentage of points with constant contact was still observed to be significantly higher during AF than during SR $(p<0.01)$ 


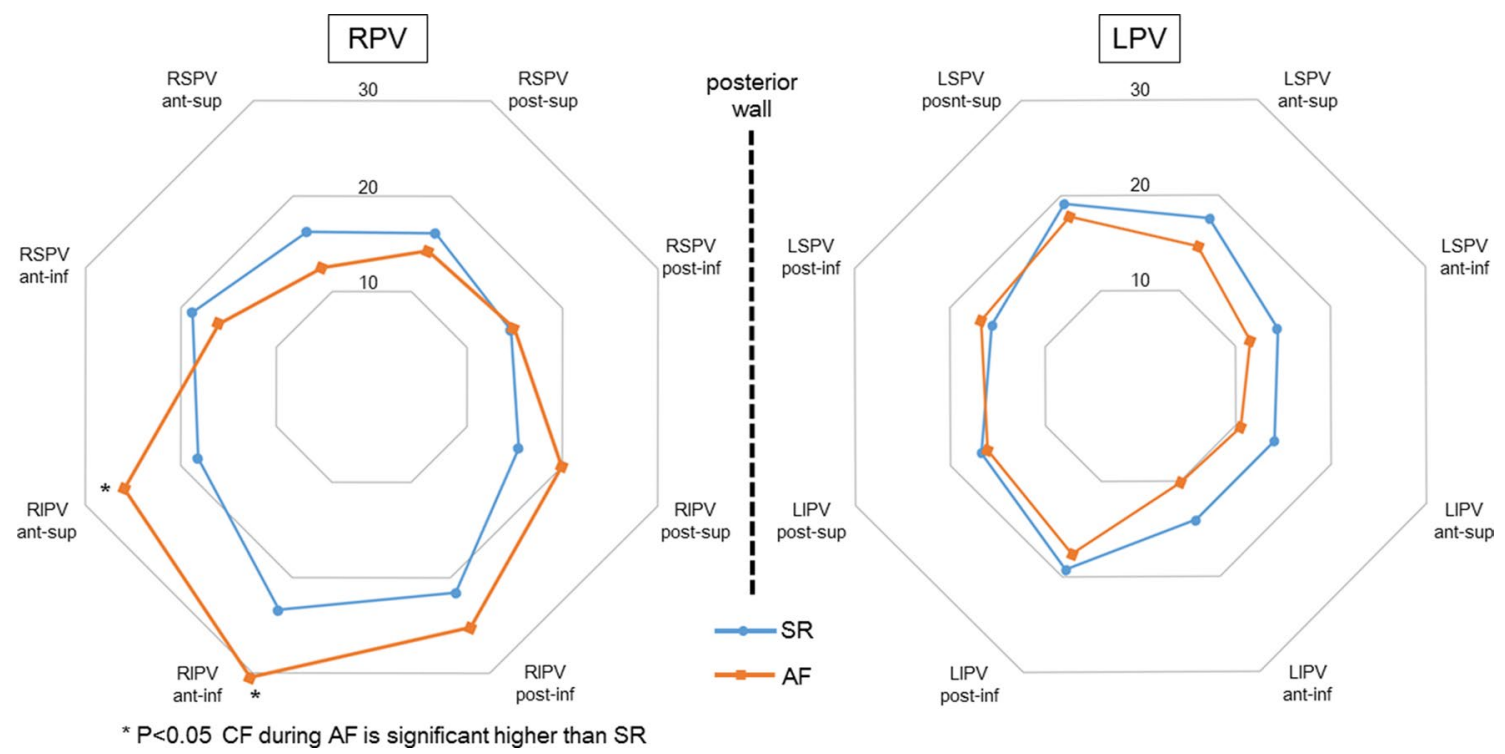

Fig. 6 Average CF (g) during SR and AF per each anatomical location. Average CF at the RPV was significantly higher than at the LPV during both atrial rhythms. Lowest CF was observed from anteriorinferior of LSPV and down to anterior-inferior of LIPV (LA ridge area). No significant difference of average CF between atrial rhythms has been shown at the LA ridge area. Although anterior part of RIPV has the tendency to achieve high tissue contact during both atrial

\section{Discussion}

Our study has demonstrated that (1) average CF showed no significant difference between SR and AF; (2) regardless of the atrial rhythm, there was a high variability of average CF; (3) there was no significant difference in the ratio of either low contact or sufficient contact; however, the ratio of excessive contact was significantly higher during $\mathrm{AF}$ than during $\mathrm{SR}$; (4) constant contact was more often achievable during AF than during SR; (5) there was no significant difference in the average CF between atrial rhythms according to the anatomical location except at the RIPV anterior area.

To the best of our knowledge, this study is the first systematic, prospective analysis of $\mathrm{CF}$ during different atrial rhythms (SR vs AF).

\section{Average CF and contact type according to atrial rhythm}

Average CF varied widely during both atrial rhythms in the present study. We have demonstrated that there was no significant difference in average $\mathrm{CF}$ between atrial rhythms when CF information was blinded to the operators. Some clinical trials $[3,4]$ showed that average CF correlates with clinical outcome in patients with $\mathrm{AF}$ undergoing RF using CF-sensing catheters. We have shown here that rhythms, average CF during AF was significantly higher than SR at the anterior part of RIPV. Except for location at the anterior part of the RIPV, there was no significant difference of average CF seen between atrial rhythms: $R P V$ right pulmonary vein, $L P V$ left pulmonary vein, $R S P V$ right superior pulmonary vein, $R I P V$ right inferior pulmonary vein, $L S P V$ left superior pulmonary vein, $L I P V$ left inferior pulmonary vein, $S R$ sinus rhythm, $A F$ atrial fibrillation

low contact occurs during both atrial rhythms to the same degree $(p=0.18)$, and only $34 \%$ points were categorized as sufficient contact during both atrial rhythms $(34.6 \%$ during SR, $34.2 \%$ during $\mathrm{AF}, p=0.51$ ) when operators are blinded to $\mathrm{CF}$ information. On the other hand, excessive $\mathrm{CF}$ of more than $40 \mathrm{~g}$ is associated with potentially major complications, such as cardiac perforation or steam pop [10, 11]. In an animal model, a CF below $40 \mathrm{~g}$ did not result in any perforation [12]. In our study, more than $7 \%$ points during $\mathrm{AF}$ came into excessive $\mathrm{CF}$ category, while just $4.2 \%$ points during SR were categorized as an excessively high contact. The distribution of excessive contact was significantly higher during AF than during SR.

The results of the present study could be explained by the indication of two aspects, that is, (1) the difference of the atrial contractility and (2) the difference of indirect CF information.

Compared to the regular atrial contraction during SR, the atrial contractile function is diminished during AF due to very high frequent electrical activity. With no atrial contraction, stable catheter tissue contact might be more often achievable during AF than during SR. Accordingly, we could demonstrate that constant contact was more often achievable during AF than it was during SR although an average $\mathrm{CF}$ was not seen to be different between both rhythms. This result could be explained by the difference of atrial contractility between atrial rhythms. 


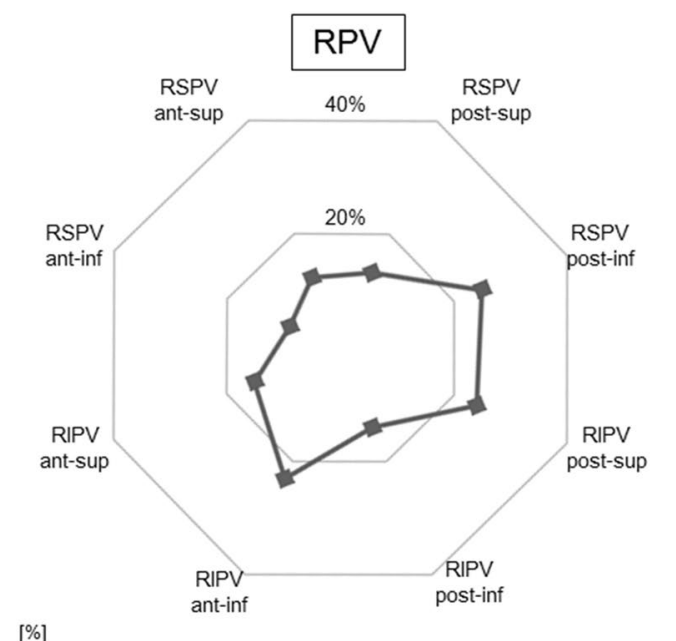

$[\%]$

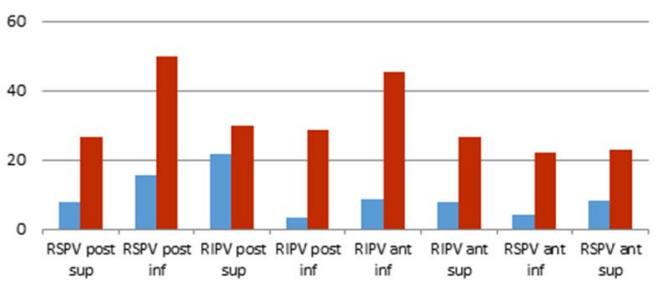

Fig. 7 The percentage of points with constant contact according to anatomical location. Upper part the proportion of constant contact in all data points. Small percentage of the achievement of constant contact was shown in the ridge area $(9.8 \%$ at anterior-inferior of LSPV and $12.2 \%$ at anterior-inferior of LIPV). Lower part the percentage

The second factor which may influence tissue contact is the indirect information on $\mathrm{CF}$ which the operators have to rely on during the procedure. This study was performed with the operators blinded to the CF information. When operators have no access to direct and real-time CF information, the information about tissue contact which they do have is limited to indirect parameters. Fluoroscopic visualization of catheter tip or tactile feedback from catheter manipulation are assessed subjectively $[13,14]$. Other conventional parameters such as impedance or amplitude of the local electrogram can be used as alternative markers of tissue contact. However, the accuracy of these indirect parameters has not been well validated and it has been postulated that they correlate poorly with tissue contact $[10$, 15-18]. As shown in a previous study [19], the amplitude or width of the local electrogram is quite different between $\mathrm{SR}$ and AF. Due to the very high frequent atrial electrical activity during AF, it is more difficult to recognize the local electrogram compared with that of SR. This difficulty in interpretation of catheter tip electrogram during $\mathrm{AF}$ may not only lead to insufficient contact but also has the potential of excessive contact when no $\mathrm{CF}$ information is available.
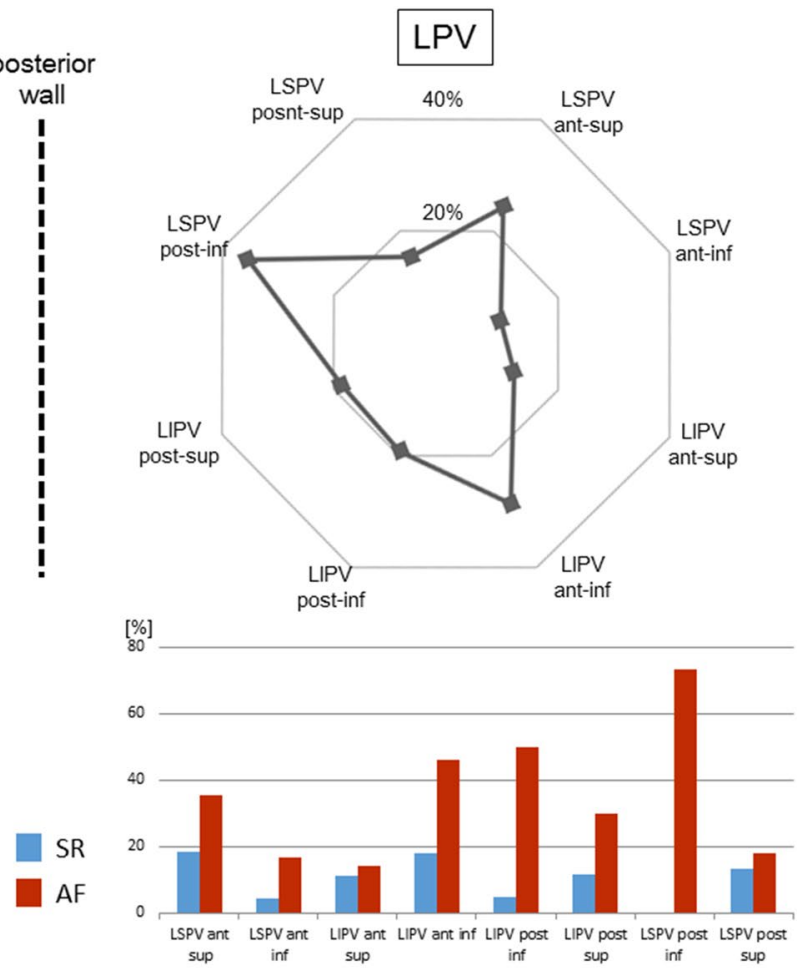

of points with constant contact per each anatomical location according to atrial rhythm. Except for location at the posterior superior of LSPV ( $p=0.18$ ), the percentage of constant contact was significantly higher during AF than it was during SR $(p<0.05)$. The abbreviations used here are same as those used in Fig. 6

A previous study using $\mathrm{CF}$ sensing catheters in a contractile bench model demonstrated that constant contact produces the largest lesions in comparison with variable contact or intermittent contact [20]. In the present study we were able to show that stable tissue contact is more often achievable during AF, which might lead to larger and longer lasting lesions. This hypothesis has to be confirmed in future trials together with the utilization of larger sample sizes.

\section{CF during AF and SR according to anatomical location}

Influences of the anatomical situation on CF were recently reported $[3,4,6]$. In these previous studies, average $\mathrm{CF}$ has been shown to be generally higher at the RPV than at the LPV. The present study demonstrated also a higher average $\mathrm{CF}$ at the RPV regardless of atrial rhythm. This study also showed that the lowest CF is at the LA ridge area. This result is also in accordance with previous studies [3, $4,6]$. No significant difference of average CF between atrial rhythms has been shown at the LA ridge area. This anatomical location is the most difficult location where one can achieve sufficient tissue contact due to complex 
anatomical situation, which is located between LPV and left atrial appendage. Inadequate $\mathrm{CF}$ leads to insufficient lesion and results in acute PV reconnection [5, 14]. It is well known that $\mathrm{PV}$ reconnection plays an important role in clinical recurrence of AF after RFCA of AF [21-23]. Low average $\mathrm{CF}$ and the small percentage of constant contact at the ridge area may explain the high rate of $\mathrm{PV}$ reconnection in this region [24]. The wall thickness of the LA ridge area has been shown to be an independent predictor of an $\mathrm{AF}$ recurrence [25]. At this area, CF information may yield an important additional value during both atrial rhythms.

At the anterior part of RIPV, the highest average CF of all positions was achieved. This location was the only area where the average $\mathrm{CF}$ showed any statistical difference between atrial rhythms (average $\mathrm{CF}$ was higher during $\mathrm{AF}$ than SR, $p<0.05$ ). This area has a tendency to achieve high tissue contact. Previous studies have also shown high average $\mathrm{CF}$ in this area $[4,6]$. Due to the close proximity to the transseptal puncture site, a more rigid fulcrum is used to achieve stability of the ablation catheter. Furthermore, maximum catheter deflection combined with a deflectable sheath may result in high CF when targeting the anterior part of RIPV. The anatomical relationship between ascending aorta and anterior LA is also considered to be a reason for high CF. When the ablation catheter is located directly beneath the ascending aorta, it exerts an external force against the LA wall and the ablation catheter [16]. In addition to these anatomical factors, the tendency of stable tissue contact and the difficulty of recognition of catheter tip electrogram during AF may have a potential of excessive contact when no CF information is provided. The present study suggests that particular caution should be taken in order to prevent excessive contact force when RFCA is performed at this area during AF. The real-time CF information to avoid excessive contact may potentially reduce the risk of major complications.

\section{Study limitations}

There are several limitations of the study which should be acknowledged. First, this study was designed to assess the influence of atrial rhythm upon CF and has not attempted to indicate any clinical outcome. The impact of CF guided RFCA on the clinical outcome was recently reported [26, 27]. Although our objective was to evaluate the influence of atrial rhythm upon CF prospectively, the findings suggest that the additional CF information may bring an important value. Secondly, the procedures were performed under deep sedation rather than under general anesthesia. Although this is an acceptable mode of sedation during RFCA of AF, the differences of respiratory condition between patients may have added an uncontrolled variable to this study. Thirdly, not only was the sample volume relatively small, the study was performed in a single center. However, we were still able to find out the statistically meaningful differences with these relatively small numbers suggesting that atrial rhythm influences the CF. Larger, multicenter studies are required to confirm our initial results.

\section{Conclusion}

Although average CF was not different between atrial rhythms, constant contact was more often achievable during $\mathrm{AF}$ than it was during SR. However, excessive $\mathrm{CF}$ also seems to occur more frequently during AF especially at the anterior part of RIPV during $\mathrm{AF}$ when no $\mathrm{CF}$ information is provided.

\section{Compliance with ethical standards}

Conflict of interest The authors declare that there is no conflict of interest.

Open Access This article is distributed under the terms of the Creative Commons Attribution 4.0 International License (http://creativecommons.org/licenses/by/4.0/), which permits unrestricted use, distribution, and reproduction in any medium, provided you give appropriate credit to the original author(s) and the source, provide a link to the Creative Commons license, and indicate if changes were made.

\section{References}

1. Calkins H, Kuck KH, Cappato R, Brugada J, Camm AJ, Chen SA, Crijns HJ, Damiano RJ Jr, Davies DW, DiMarco J, Edgerton J, Ellenbogen K, Ezekowitz MD, Haines DE, Haissaguerre M, Hindricks G, Iesaka Y, Jackman W, Jalife J, Jais P, Kalman J, Keane D, Kim YH, Kirchhof P, Klein G, Kottkamp H, Kumagai K, Lindsay BD, Mansour M, Marchlinski FE, McCarthy PM, Mont JL, Morady F, Nademanee K, Nakagawa H, Natale A, Nattel S, Packer DL, Pappone C, Prystowsky E, Raviele A, Reddy V, Ruskin JN, Shemin RJ, Tsao HM, Wilber D (2012) 2012 HRS/ EHRA/ECAS expert consensus statement on catheter and surgical ablation of atrial fibrillation: recommendations for patient selection, procedural techniques, patient management and follow-up, definitions, endpoints, and research trial design. Heart Rhythm 9:632-696

2. Thiagalingam A, D'Avila A, Foley L, Guerrero JL, Lambert H, Leo G, Ruskin JN, Reddy VY (2010) Importance of catheter contact force during irrigated radiofrequency ablation: evaluation in a porcine ex vivo model using a force-sensing catheter. $\mathbf{J}$ Cardiovasc Electrophysiol 21:806-811

3. Reddy VY, Shah D, Kautzner J, Schmidt B, Saoudi N, Herrera C, Jaïs P, Hindricks G, Peichl P, Yulzari A, Lambert H, Neuzil P, Natale A, Kuck KH (2012) The relationship between contact force and clinical outcome during radiofrequency catheter ablation of atrial fibrillation in the TOCCATA study. Heart Rhythm 9:1789-1795

4. Neuzil P, Reddy VY, Kautzner J, Petru J, Wichterle D, Shah D, Lambert H, Yulzari A, Wissner E, Kuck KH (2013) Electrical 
reconnection after pulmonary vein isolation is contingent on contact force during initial treatment: results from the EFFICAS I study. Circ Arrhythm Electrophysiol 6:327-333

5. Park CI, Lehrmann H, Keyl C, Weber R, Schiebeling J, Allgeier J, Schurr P, Shah A, Neumann FJ, Arentz T, Jadidi AS (2014) Mechanisms of pulmonary vein reconnection after radiofrequency ablation of atrial fibrillation: the deterministic role of contact force and interlesion distance. J Cardiovasc Electrophysiol 25:701-708

6. Kumar S, Morton JB, Lee J, Halloran K, Spence SJ, Gorelik A, Hepworth G, Kistler PM, Kalman JM (2012) Prospective characterization of catheter-tissue contact force at different anatomic sites during antral pulmonary vein isolation. Circ Arrhythm Electrophysiol 5:1124-1129

7. Kumar S, Morton JB, Halloran K, Spence SJ, Lee G, Wong MC, Kistler PM, Kalman JM (2012) Effect of respiration on cathetertissue contact force during ablation of atrial arrhythmias. Heart Rhythm 9:1041-1047

8. Maeno K, Kasai T, Kasagi S, Kawana F, Ishiwata S, Ohno M, Yamaguchi T, Narui K (2013) Relationship between atrial conduction delay and obstructive sleep apnea. Heart Vessels 28:639-645

9. Kuck KH, Reddy VY, Schmidt B, Natale A, Neuzil P, Saoudi N, Kautzner J, Herrera C, Hindricks G, Jaïs P, Nakagawa H, Lambert H, Shah DC (2012) A novel radiofrequency ablation catheter using contact force sensing: Toccata study. Heart Rhythm 9:18-23

10. Yokoyama K, Nakagawa H, Shah DC, Lambert H, Leo G, Aeby N, Ikeda A, Pitha JV, Sharma T, Lazzara R, Jackman WM (2008) Novel contact force sensor incorporated in irrigated radiofrequency ablation catheter predicts lesion size and incidence of steam pop and thrombus. Circ Arrhythm Electrophysiol $1: 354-362$

11. Di Biase L, Natale A, Barrett C, Tan C, Elayi CS, Ching CK, Wang P, Al-Ahmad A, Arruda M, Burkhardt JD, Wisnoskey BJ, Chowdhury P, De Marco S, Armaganijan L, Litwak KN, Schweikert RA (2009) Relationship between catheter forces, lesion characteristics, "popping," and char formation: experience with robotic navigation system. J Cardiovasc Electrophysiol 20:436-440

12. Perna F, Heist EK, Danik SB, Barrett CD, Ruskin JN, Mansour M (2011) Assessment of catheter tip contact force resulting in cardiac perforation in swine atria using force sensing technology. Circ Arrhythm Electrophysiol 4:218-224

13. Gaspar T, Sih H, Hindricks G, Eitel C, Sommer P, Kircher S, Rolf S, Arya A, Teplitsky L, Piorkowski C (2013) Use of electrical coupling information in $\mathrm{AF}$ catheter ablation: a prospective randomized pilot study. Heart Rhythm 10:176-181

14. Haldar S, Jarman JW, Panikker S, Jones DG, Salukhe T, Gupta D, Wynn G, Hussain W, Markides V, Wong T (2013) Contact force sensing technology identifies sites of inadequate contact and reduces acute pulmonary vein reconnection: a prospective case control study. Int J Cardiol 168:1160-1166

15. Holmes D, Fish JM, Byrd IA, Dando JD, Fowler SJ, Cao H, Jensen JA, Puryear HA, Chinitz LA (2011) Contact sensing provides a highly accurate means to titrate radiofrequency ablation lesion depth. J Cardiovasc Electrophysiol 22:684-690

16. Nakagawa H, Kautzner J, Natale A, Peichl P, Cihak R, Wichterle D, Ikeda A, Santangeli P, Di Biase L, Jackman WM (2013) Locations of high contact force during left atrial mapping in atrial fibrillation patients: electrogram amplitude and impedance are poor predictors of electrode-tissue contact force for ablation of atrial fibrillation. Circ Arrhythm Electrophysiol 6:746-753
17. Kumar S, Chan M, Lee J, Wong MC, Yudi M, Morton JB, Spence SJ, Halloran K, Kistler PM, Kalman JM (2014) Cathetertissue contact force determines atrial electrogram characteristics before and lesion efficacy after antral pulmonary vein isolation in humans. J Cardiovasc Electrophysiol 25:122-129

18. Ikeda A, Nakagawa H, Lambert H, Shah DC, Fonck E, Yulzari A, Sharma T, Pitha JV, Lazzara R, Jackman WM (2014) Relationship between catheter contact force and radiofrequency lesion size and incidence of steam pop in the beating canine heart: electrogram amplitude, impedance, and electrode temperature are poor predictors of electrode-tissue contact force and lesion size. Circ Arrhythm Electrophysiol 7:1174-1180

19. Hoshiyama T, Yamabe H, Koyama J, Kanazawa H, Ogawa $H$ (2015) Left atrial electrophysiologic feature specific for the genesis of complex fractionated atrial electrogram during atrial fibrillation. Heart Vessels. doi:10.1007/s00380-015-0672-2

20. Shah DC, Lambert H, Nakagawa H, Langenkamp A, Aeby N, Leo G (2010) Area under the real-time contact force curve (force-time integral) predicts radiofrequency lesion size in an in vitro contractile model. J Cardiovasc Electrophysiol 21:1038-1043

21. Verma A, Kilicaslan F, Pisano E, Marrouche NF, Fanelli R, Brachmann J, Geunther J, Potenza D, Martin DO, Cummings J, Burkhardt JD, Saliba W, Schweikert RA, Natale A (2005) Response of atrial fibrillation to pulmonary vein antrum isolation is directly related to resumption and delay of pulmonary vein conduction. Circulation 112:627-635

22. Cappato R, Negroni S, Pecora D, Bentivegna S, Lupo PP, Carolei A, Esposito C, Furlanello F, De Ambroggi L (2003) Prospective assessment of late conduction recurrence across radiofrequency lesions producing electrical disconnection at the pulmonary vein ostium in patients with atrial fibrillation. Circulation 108:1599-1604

23. Arya A, Hindricks G, Sommer P, Huo Y, Bollmann A, Gaspar T, Bode K, Husser D, Kottkamp H, Europace Piorkowski C (2010) Long-term results and the predictors of outcome of catheter ablation of atrial fibrillation using steerable sheath catheter navigation after single procedure in 674 patients. Europace 12:173-180

24. Rajappan K, Kistler PM, Earley MJ, Thomas G, Izquierdo M, Sporton SC, Schilling RJ (2008) Acute and chronic pulmonary vein reconnection after atrial fibrillation ablation: a prospective characterization of anatomical sites. Pacing Clin Electrophysiol 31:1598-1605

25. Suenari K, Nakano Y, Hirai Y, Ogi H, Oda N, Makita Y, Ueda S, Kajihara K, Tokuyama T, Motoda C, Fujiwara M, Chayama K, Kihara Y (2013) Left atrial thickness under the catheter ablation lines in patients with paroxysmal atrial fibrillation: insights from 64-slice multidetector computed tomography. Heart Vessels 28:360-368

26. Wutzler A, Huemer M, Parwani AS, Blaschke F, Haverkamp W, Boldt LH (2014) Contact force mapping during catheter ablation for atrial fibrillation: procedural data and one-year follow-up. Arch Med Sci 10:266-272

27. Marijon E, Fazaa S, Narayanan K, Guy-Moyat B, Bouzeman A, Providencia R, Treguer F, Combes N, Bortone A, Boveda S, Combes S, Albenque JP (2014) Real-time contact force sensing for pulmonary vein isolation in the setting of paroxysmal atrial fibrillation: procedural and 1-year results. J Cardiovasc Electrophysiol 25:130-137 